\title{
Guar gum (GG) / Methylcellulose (MC) Blends and their Composites with Maghemite Nanoparticles
}

\author{
M. S. Bhavya, K. S. Sudhanva Narayana, M. B. Savitha, P. Prasad
}

\begin{abstract}
Miscibility of polymers decides the applicability of the resulting blends and immiscible polymer blends can be made compatible with suitable compatibilizer. Miscibility of blends of guar gum (GG) and methyl cellulose (MC) in common solvent water were studied by refractive index, density, ultrasonic velocity, and dilute solution viscometry methods at $30^{\circ} \mathrm{C}$ and $40^{\circ} \mathrm{C}$. Based on these measurements, it is found that the polymer blend of GG/MC is immiscible. The effect of compatibilization with 0.02 $w t \%$ maghemite nanoparticle was studied in aqueous solution and found that 10/90 GG/MC blend is miscible in the presence of maghemite. Solution cast technique was used to prepare thin films of GG/MC blend - maghemite composite and characterized by scanning electron microscopy (SEM), and Fourier transform infrared spectroscopy (FTIR) method.
\end{abstract}

Keywords: guar gum, maghemite, miscibility, methylcellulose, polymer blends.

\section{INTRODUCTION}

$\mathrm{P}_{\text {olymer blends are tailor-made materials for specific }}$ applications. The researches on polymer blends have gained considerable interest due to the reduction in the cost of production, improved processability, and improved properties [1]. The blending of polymers is significant to obtain a variety of physical and chemical properties from the constituent polymers [2]. The blend property depends on the polymer-polymer miscibility. Based on the miscibility, polymer blends are classified as miscible, semi-miscible, and immiscible blends [3]. Extensive studies on the miscibility of polymer blends by different techniques have been reported earlier by different researchers [4-8]. The miscibility of polymer blends is studied and confirmed by using density, refractive index, ultrasonic interferometry, viscometry, scanning electron microscopy (SEM) and Fourier transform

Revised Manuscript Received on May 15, 2020.

* Correspondence Author

Bhavya M. S., Nano Science and Technology, College of Engineering and Technology, Srinivas University, Mangaluru, India. Email: bhavyshekar111@gmail.com

Sudhanva Narayana K. S., Department of Nano Technology, Srinivas Institute of Technology, Mangaluru, India. Email: natekallusudhanva@gmail.com

Savitha M. B., Department of Chemistry and Research Centre, Sahyadri College of Engineering and Management, Adyar, Mangaluru, India. Email: savitha.chem@sahyadri.edu.in

Prasad P*., Nano Science and Technology, College of Engineering and Technology, Srinivas University, Mangaluru, India. Email: hodnanotechsit@gmail.com

(C) The Authors. Published by Blue Eyes Intelligence Engineering and Sciences Publication (BEIESP). This is an open access article under the CC BY-NC-ND license (http://creativecommons.org/licenses/by-nc-nd/4.0/) infrared spectroscopic (FTIR) methods [9-17].

Guar gum (GG) is an extremely hydrophilic natural polymer with high viscosity. This property has allowed GG to be commercialized in fields such as textiles, foods, cosmetics, pharmaceuticals and oil recovery and drilling [13, 15]. Methylcellulose is a semi-synthetic water-soluble polymer derived from cellulose and is used as a thickener in the food industry, and as a matrix for the controlled release of drugs in the pharmaceutical industry [18].

Polymer blends of GG and MC will be having potential applications in drug release formulations. The miscibility can be enhanced by the incorporation of suitable compatible agents [11]. Maghemite is a biocompatible magnetic nanoparticle having potential applications in the biomedical field [19-22]. In this work miscibility of guar gum and methylcellulose at different compositions were studied in solution state at $30^{\circ} \mathrm{C}$ and $40^{\circ} \mathrm{C}$ by refractive index, density, ultrasonic velocity, and viscosity measurement techniques in aqueous solution and by SEM and FTIR in solid-state. The effect of biocompatible maghemite nanoparticles (Mag NPs) on the miscibility of GG/MC blends was studied in aqueous solution by density, ultrasonic velocity, dilute solution viscometry in aqueous solution and in the solid-state by SEM, and FTIR.

\section{EXPERIMENTAL PROCEDURE}

The polymers employed in the present study are guar gum (GG), methylcellulose (MC), and the nanoparticle used is maghemite. All were purchased from Merck, India. Schematic representation of guar gum and methylcellulose are shown in Fig. 1, and 2, respectively.

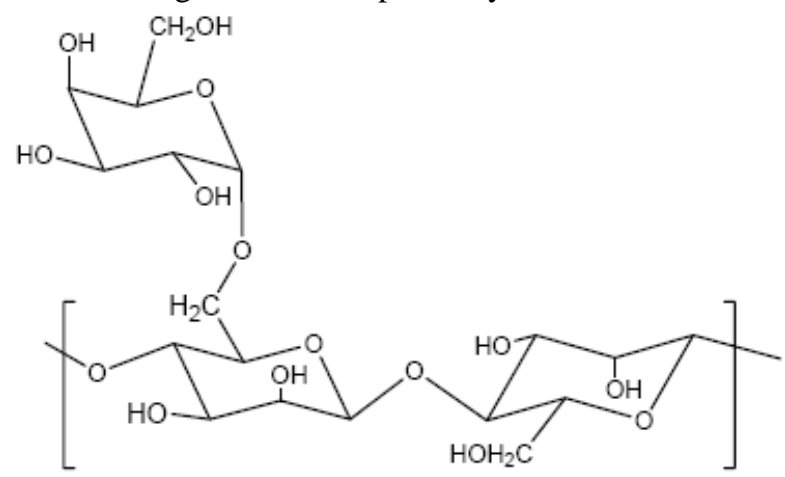

Fig. 1: Schematic representation of guar gum 


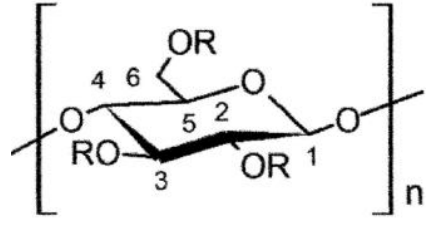

$\mathrm{R}=\mathrm{H}$ or $\mathrm{R}=\mathrm{CH}_{3}$

Fig. 2: Schematic representation of methylcellulose

0.01, 0.02, 0.03, 0.04, and 0.05 wt\% maghemite nanocomposites were prepared with guar gum $(0.5 \% \mathrm{w} / \mathrm{v})$ and with methylcellulose $(0.5 \% \mathrm{w} / \mathrm{v})$ separately in distilled water as solvent. The mixtures were mechanically stirred for 6 hours in a polymer mixer and were further kept for ultrasonication for 4 hours to ensure uniform mixing. The prepared samples were taken in test tubes and kept in contact with a strong magnet for 30 minutes to check the stability of the solution. All the maghemite-MC composite solutions showed stability towards the magnetic field, whereas the solutions of guar gum containing $0.05,0.04$, and $0.03 \mathrm{wt} \%$ of maghemite, the maghemite got settled along the sides of the test tube attracted by the strong magnet. Hence the experiments were continued with $0.02 \mathrm{wt} \%$ of maghemite.

Blends of GG/MC of different compositions (10/90, 30/70, 50/50, 70/30, and 90/10) were prepared in distilled water. The refractive index, density, and ultrasonic velocity of the GG, MC, GG/MC blend solutions $(0.5 \%$, w/v) with and without maghemite nanoparticles $(0.02 \mathrm{wt} \%)$ were measured at $30^{\circ} \mathrm{C}$ and $40^{\circ} \mathrm{C}$ using specific gravity bottle, Abbe's refractometer, and ultrasonic interferometer (Model F-81, Mittal Enterprises, India), respectively. Different temperatures were maintained using a thermostat bath with a thermal stability of $\pm 0.05^{\circ} \mathrm{C}$.

Stock solutions of GG, GG - maghemite composite, MC, and $\mathrm{MC}$ - maghemite composite were prepared $(0.1 \% \mathrm{w} / \mathrm{v}$ of polymer). The maghemite composition was maintained at 0.02 wt\%. The blend stock solutions (10/90, 30/70, 50/50, 70/30 and 90/10) and blend - maghemite composite stock solutions (10/90, 30/70, 50/50, 70/30 and 90/10) were prepared by stirring the mixtures at room temperature for about 45 minutes. With the above pure and blend stock solutions, different dilute blend solutions $(0.01,0.02,0.03$, $0.04,0.05,0.06,0.07,0.08,0.09$ and $0.1 \mathrm{w} / \mathrm{v}$ concentrations) were prepared. Dilute solution viscosity measurements were done at $30^{\circ} \mathrm{C}$ and $40^{\circ} \mathrm{C}$ using an Ubbelohde suspended level viscometer. Different temperatures were maintained using a thermostat bath with a thermal stability of $\pm 0.05^{\circ} \mathrm{C}$.

Thin films of polymer/polymer blend - maghemite composites were prepared by solution casting technique for characterization purposes. SEM photographs were recorded using a ZEISS Sigma FESEM 300 analyzer and FTIR spectra were recorded using NICOLET AVATAR 530 spectrophotometer.

\section{A. Refractive index measurements}

The refractive index (RI) values of pure polymers and their blends were measured. The RI value for MC is 1.3420 and 1.3410 , and for GG is 1.3402 and 1.3385 at $30^{\circ} \mathrm{C}$ and $40^{\circ} \mathrm{C}$, respectively. A slight linearity is observed for the $10 / 90$

\section{RESULTS AND DISCUSSIONS}

GG/MC blend compared with RI values of pure GG and MC both at $30^{\circ} \mathrm{C}$ and $40^{\circ} \mathrm{C}$ (Fig. 3). It has been well established that linearity and non-linearity of the plot indicate the miscible and immiscible nature of the blends $[9,10]$ respectively.

With the addition of 0.02 wt\% maghemite showed an RI value of about 1.46 for pure GG, MC and their blend compositions at $30^{\circ} \mathrm{C}$ and of about 1.44 at $40^{\circ} \mathrm{C}$. The higher RI value after the maghemite addition may be due to the brownish-red color of the maghemite nanoparticle and hence the RI measurement technique may not be considered as a suitable proof to assess the miscibility of the blend maghemite composites with GG and MC.

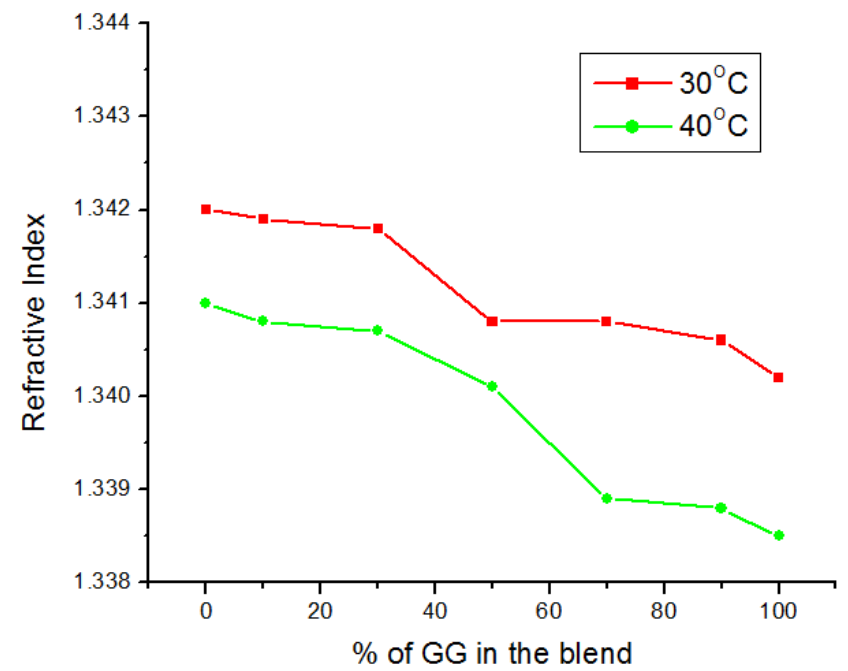

Fig. 3: Variation of refractive index of GG/MC blends in aqueous solution at $30^{\circ} \mathrm{C}$ and $40^{\circ} \mathrm{C}$

\section{B. Density measurements}

The measured density values $(\rho)$ of GG were $0.9972 \times 10^{3}$ $\mathrm{Kg} / \mathrm{m}^{3}$, and $0.99376 \times 10^{3} \mathrm{Kg} / \mathrm{m}^{3}$, and for $\mathrm{MC}$ were $0.9985 \times 10^{3} \mathrm{Kg} / \mathrm{m}^{3}$, and $0.99525 \times 10^{3} \mathrm{Kg} / \mathrm{m}^{3}$, at $30^{\circ} \mathrm{C}$ and $40^{\circ} \mathrm{C}$, respectively. The density values of blend compositions were in between that of pure GG and MC. The $\rho$ values were higher for MC compared to GG attributed to their molecular structure. The graph showed only non-linear regions indicating the immiscible nature of the GG/MC blend at both $30^{\circ} \mathrm{C}$ and $40^{\circ} \mathrm{C}$ (Fig. 4). The variation is linear for miscible and non-linear for immiscible blends [11, 12].

The recorded density values for maghemite composites were higher compared to that of pure polymers without maghemite. Density values for 0.02 wt $\%$ maghemite-GG composites were $1.007 \times 10^{3} \mathrm{Kg} / \mathrm{m}^{3}$, and $0.9985 \times 10^{3} \mathrm{Kg} / \mathrm{m}^{3}$, and for 0.02 wt\% maghemite-MC composites were $1.031 \times 10^{3} \mathrm{Kg} / \mathrm{m}^{3}$, and $1.012 \times 10^{3} \mathrm{Kg} / \mathrm{m}^{3}$, at $30^{\circ} \mathrm{C}$ and $40^{\circ} \mathrm{C}$, respectively (Fig. 5). Only 10/90 GG/MC blend - maghemite composite showed linearity compared with the maghemite composites of GG and MC, other compositions got deviated from linearity. Hence it can be concluded that the addition of maghemite improved the miscibility nature of GG/MC blends.

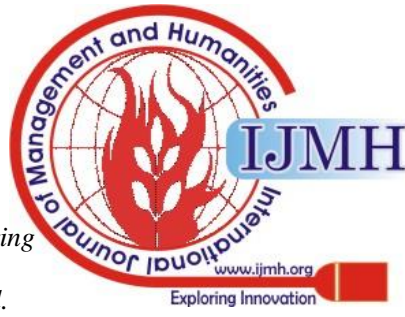




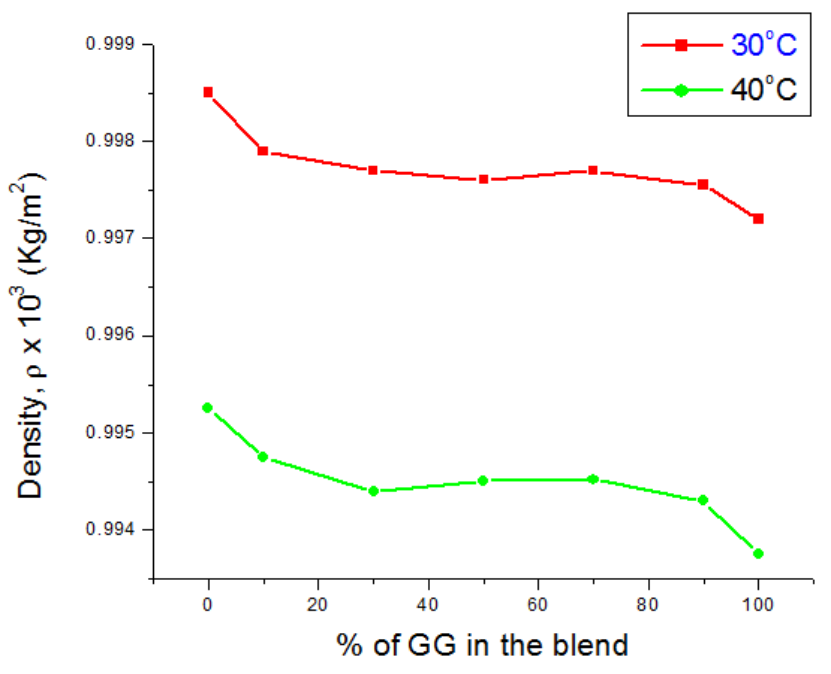

Fig. 4: Variation of density with the composition of GG/MC blend in aqueous solution at $30^{\circ} \mathrm{C}$ and $40^{\circ} \mathrm{C}$

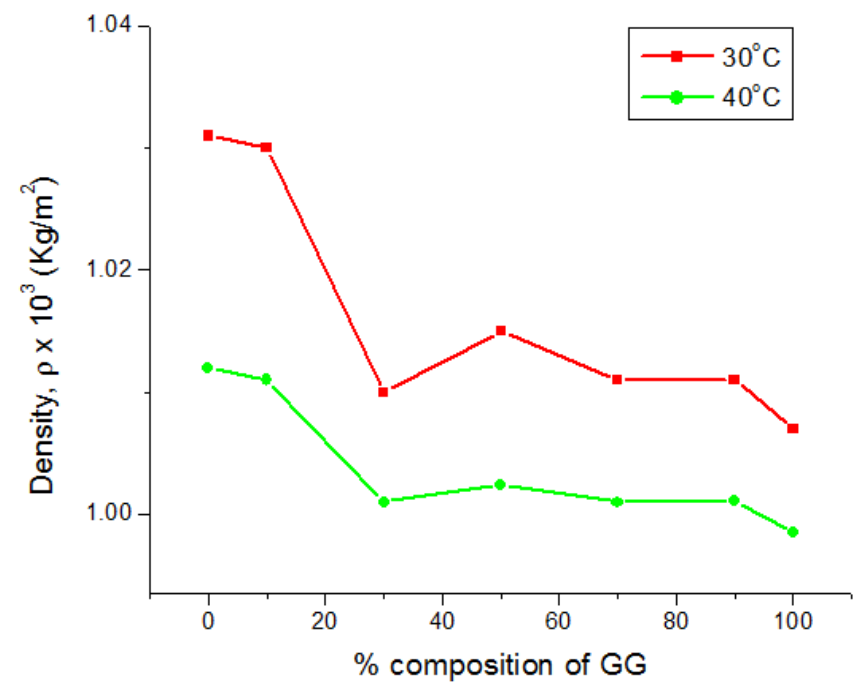

Fig. 5: Variation of density with the composition of GG/MC blend - maghemite composites in aqueous solution at $30^{\circ} \mathrm{C}$ and $40^{\circ} \mathrm{C}$

\section{Ultrasonic velocity measurements}

The measured ultrasonic velocity (v) value for methylcellulose were $1525 \mathrm{~m} / \mathrm{s}$ and $1545 \mathrm{~m} / \mathrm{s}$, and for GG were $1479 \mathrm{~m} / \mathrm{s}$ and $1519 \mathrm{~m} / \mathrm{s}$, at $30^{\circ} \mathrm{C}$ and $40^{\circ} \mathrm{C}$, respectively. The $v$ for the entire compositions were found to be in between that of pure GG and MC, but the graph showed non-linear regions (Fig. 6). This indicates that the GG/MC blend is immiscible at all compositions $[12,13]$.

The incorporation of maghemite nanoparticles decreased the $v$ of $\mathrm{GG}, \mathrm{MC}$, and $\mathrm{GG} / \mathrm{MC}$ blends. The measured values were $1510 \mathrm{~m} / \mathrm{s}$, and $1524 \mathrm{~m} / \mathrm{s}$ for MC-maghemite composite, and $1464 \mathrm{~m} / \mathrm{s}$, and $1488 \mathrm{~m} / \mathrm{s}$ for GG-maghemite composites at $30^{\circ} \mathrm{C}$ and $40^{\circ} \mathrm{C}$, respectively (Fig. 7). The observation with ultrasonic velocity measurement studies was similar to that of density studies. The presence of maghemite might have influenced the miscibility of the GG/MC blend for the 10/90 blend composition.

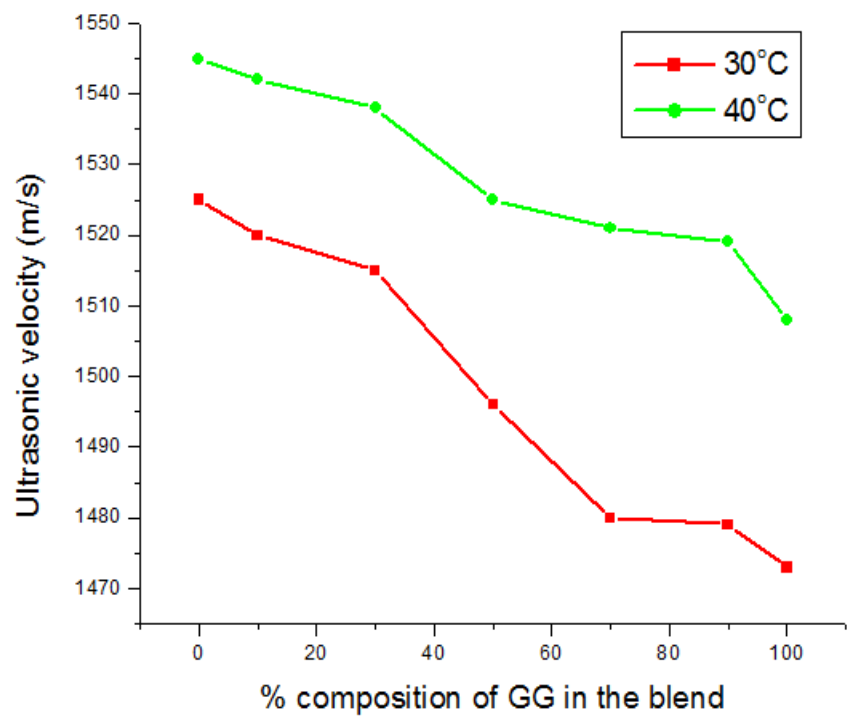

Fig. 6: Variation of ultrasonic sound velocity of GG/MC blend in aqueous solution at $30^{\circ} \mathrm{C}$ and $40^{\circ} \mathrm{C}$

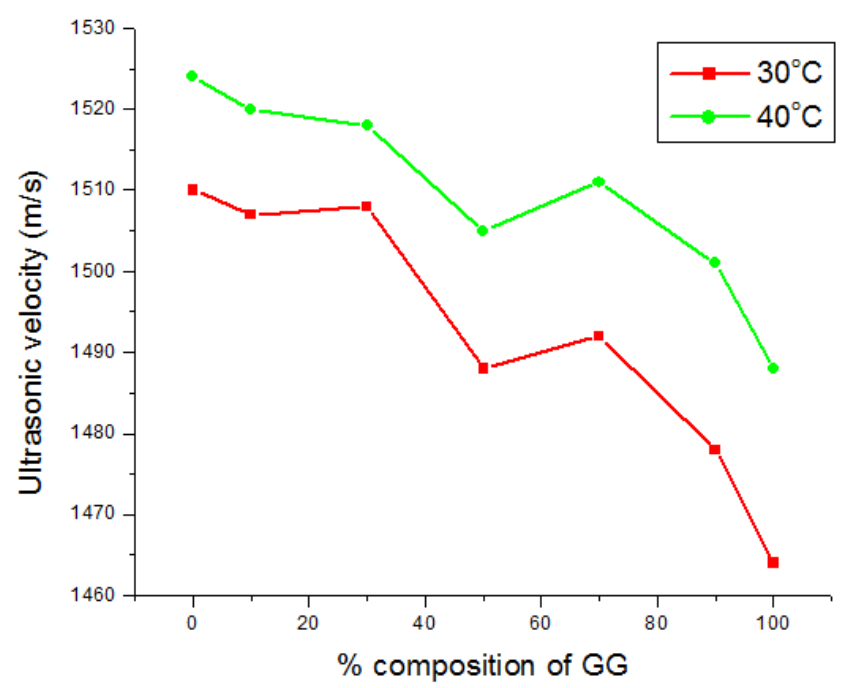

Fig. 7: Variation of ultrasonic sound velocity of GG/MC blend - maghemite composites in aqueous solution at $30^{\circ} \mathrm{C}$ and $40^{\circ} \mathrm{C}$

\section{Reduced viscosity measurements}

Reduced viscosities ( $\eta \mathrm{sp} / \mathrm{C})$ of homopolymers GG, MC and 10/90 GG/MC, 30/70 GG/MC, 50/50 GG/MC, 70/30 GG/MC, and $90 / 10 \mathrm{GG} / \mathrm{MC}$ were measured at $30^{\circ} \mathrm{C}$ and $40^{\circ} \mathrm{C}$. The Huggin's plots of $\eta_{\mathrm{sp}} / \mathrm{C}$ against concentration (C) are shown in Fig. 8 and Fig. 9, respectively. 


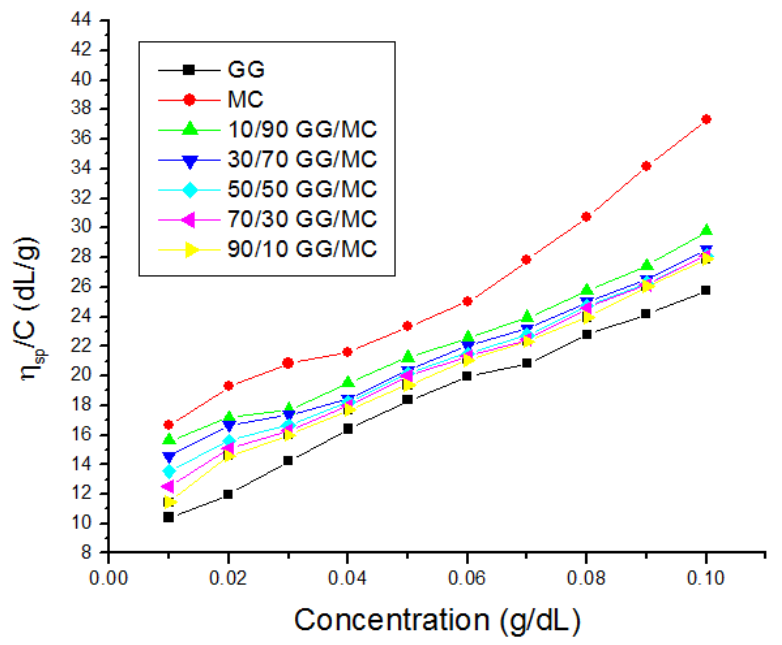

Fig. 8: Huggins's plot for GG/MC blend at $30^{\circ} \mathrm{C}$

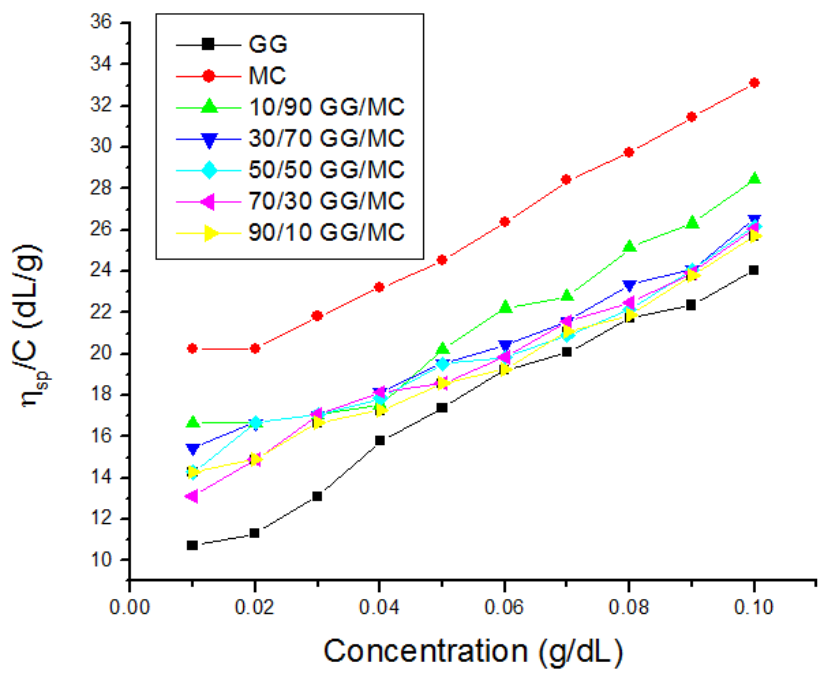

Fig. 9: Huggins's plot for GG/MC blend at $40^{\circ} \mathrm{C}$

Reduced viscosities of GG-maghemite composite, MC-maghemite composite, and the blend-maghemite composite compositions $(10 / 90,30 / 70,50 / 50,70 / 30$, and 90/10) were measured at $30^{\circ} \mathrm{C}$ and $40^{\circ} \mathrm{C} \cdot \eta_{\mathrm{sp}} / \mathrm{C}$ against concentration plots of maghemite composites are shown in Fig. 10, and Fig. 11, respectively.

From the Huggins plots the slope values were calculated and tabulated in Table I. The slope values of the blends are lower than that of pure GG and MC. This confirms phase separation of polymers in the blend. Higher slope variations for 10/90 GG/MC blend composition with maghemite nanoparticles may be attributed to the mutual attraction of macromolecules in solution which in turn leads to the increase of hydrodynamic volume [14]. The 90/10, 70/30, 50/50, and 30/70 GG/MC blend - maghemite composite compositions showed a lower slope, which may be due to the phase separation of polymers. According to the reduced viscosity-concentration [9-13] criteria, it may be concluded that this polymer blend is miscible for $10 / 90$ compositions and immiscible for 90/10, 70/30, 50/50, and 30/70 GG/MC blend compositions.

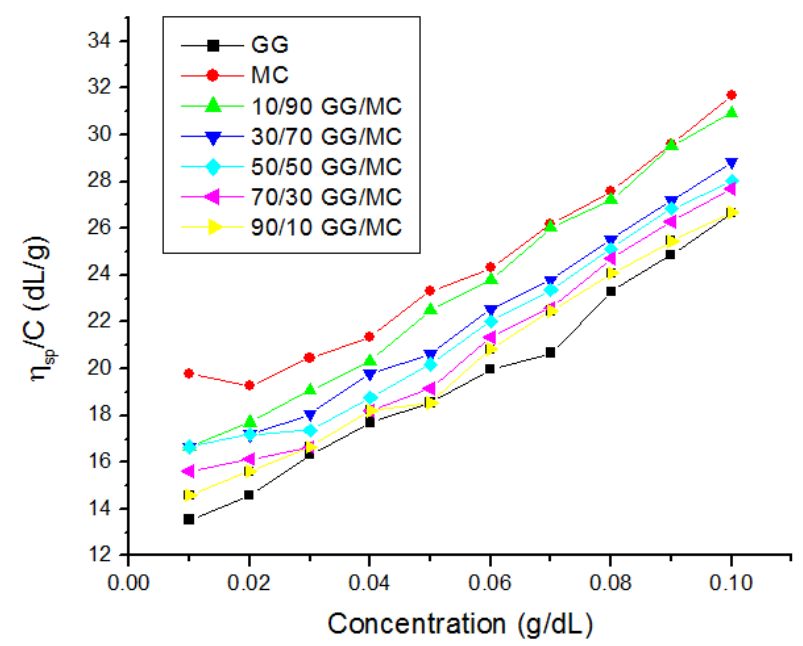

Fig. 10: Huggins's plot for GG/MC blend - maghemite composite at $30^{\circ} \mathrm{C}$

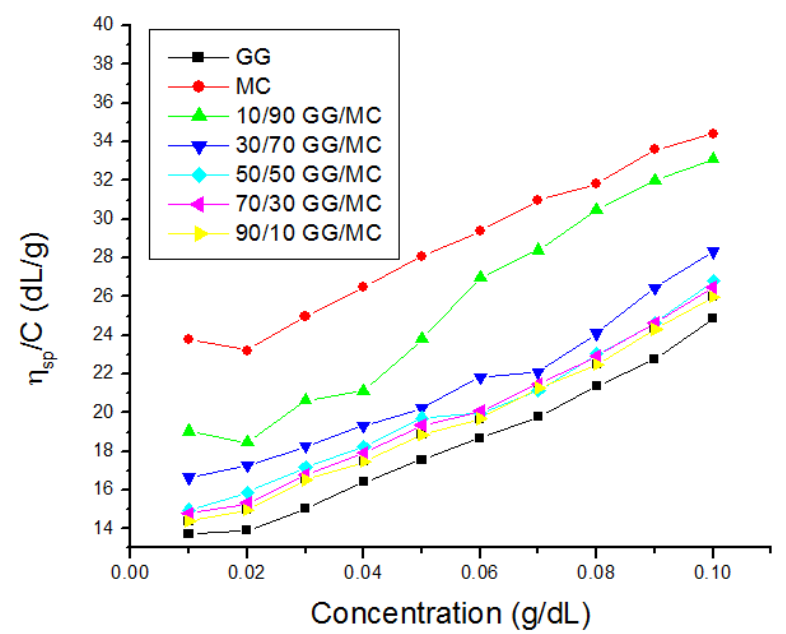

Fig. 11: Huggins's plot for GG/MC blend - maghemite composite at $40^{\circ} \mathrm{C}$

Table- I: Slope values from Huggins plots

\begin{tabular}{|c|c|c|c|c|}
\hline \multirow{2}{*}{$\begin{array}{l}\text { Blends } \\
\text { Comp. }\end{array}$} & \multicolumn{2}{|c|}{$30^{\circ} \mathrm{C}$} & \multicolumn{2}{|c|}{$40^{\circ} \mathrm{C}$} \\
\hline & $\begin{array}{c}\text { Without } \\
\text { Mag NPs }\end{array}$ & $\begin{array}{c}\text { With Mag } \\
\text { NPs }\end{array}$ & $\begin{array}{c}\text { Without } \\
\text { Mag NPs }\end{array}$ & $\begin{array}{c}\text { With } \\
\text { Mag NPs }\end{array}$ \\
\hline $0 / 100$ & 217.884 & 139.618 & 152.496 & 131.478 \\
\hline $10 / 90$ & 154.090 & 163.739 & 140.490 & 179.218 \\
\hline $30 / 70$ & 150.630 & 140.115 & 117.715 & 126.351 \\
\hline $50 / 50$ & 158.218 & 136.030 & 117.612 & 124.842 \\
\hline $70 / 30$ & 166.218 & 142.630 & 132.654 & 128.915 \\
\hline $90 / 10$ & 172.006 & 139.236 & 123.327 & 128.266 \\
\hline $100 / 0$ & 170.260 & 142.721 & 154.666 & 124.333 \\
\hline
\end{tabular}

\section{E. Morphological studies}

Morphology studies were carried out to identify the interaction between maghemite and the polymers and the influence of maghemite on the miscibility of GG/MC blend. SEM images recorded for GG, MC, and maghemite incorporated GG, MC, and 10/90 GG/MC blend (Fig. 12). The SEM images confirm that guar gum form weak interaction with maghemite, whereas the maghemite is well dispersed in methylcellulose. The 10/90 GG/MC blend with maghemite does not show any phase separation.

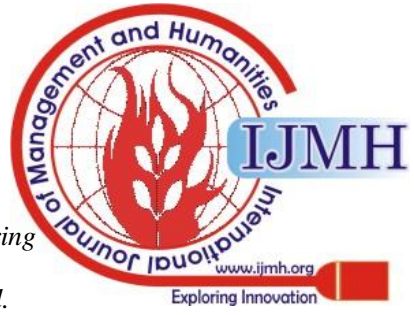


The presence of maghemite might have stabilized the structure of guar gum to form a miscible blend with MC at 10/90 blend composition.
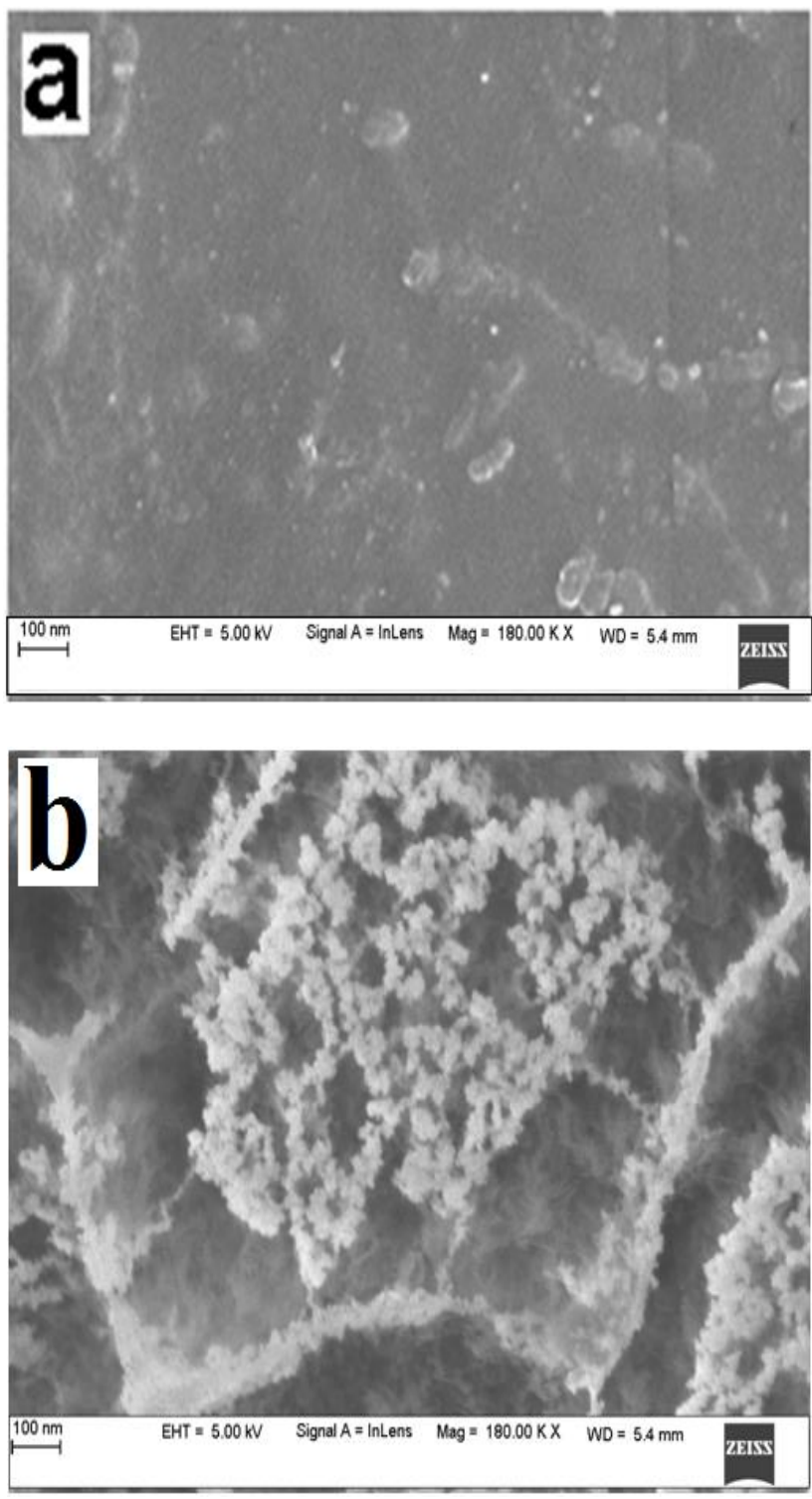

ISSN: 2394-0913 (Online), Volume-4 Issue-9, May 2020
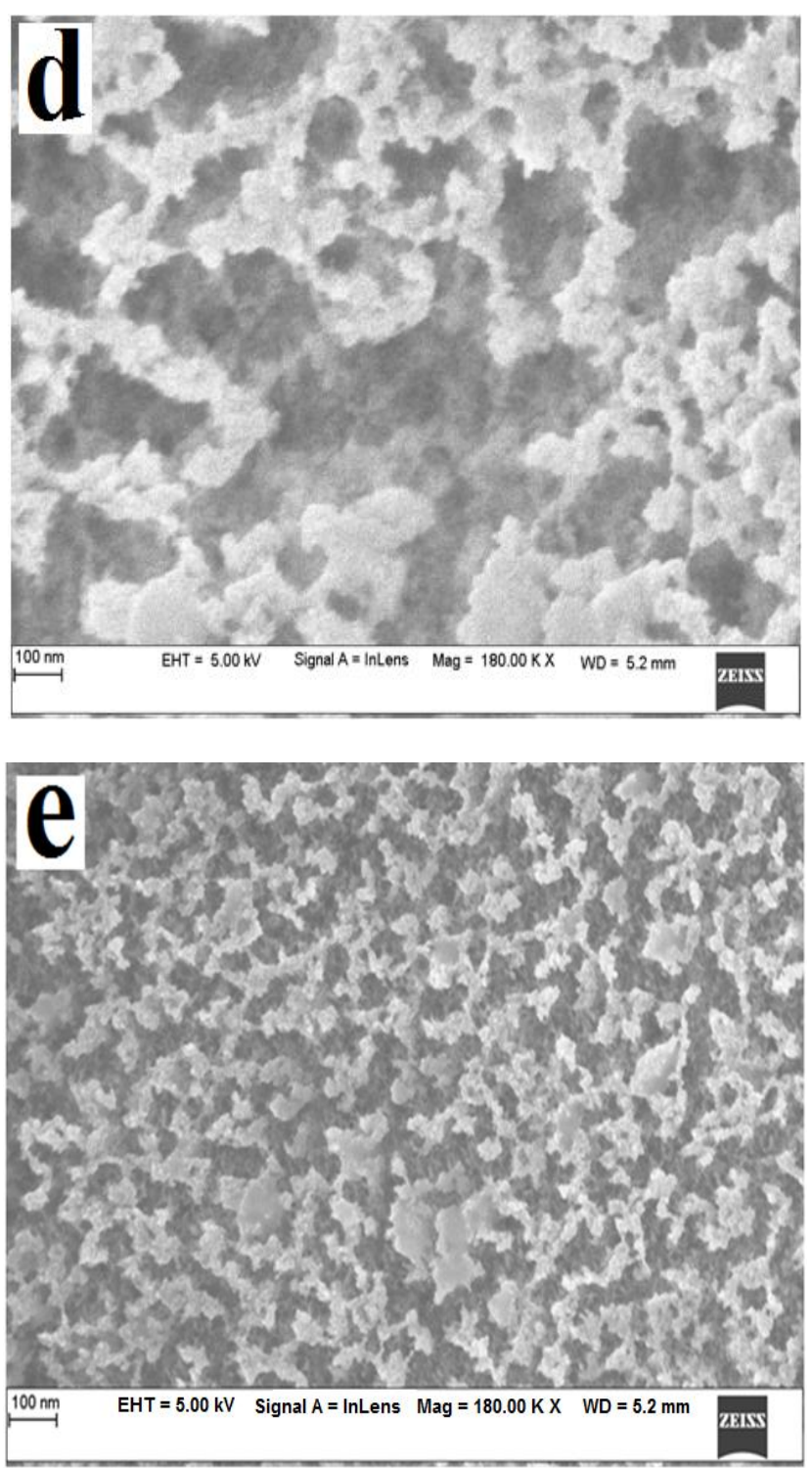

Fig. 12: SEM images of a) GG, b) GG-maghemite composite, c) MC, d) MC-maghemite composite, and e) 10/90 GG/MC blend-maghemite composite

\section{F. FTIR spectroscopic measurements}

FTIR spectra of GG, GG - maghemite composite, MC,

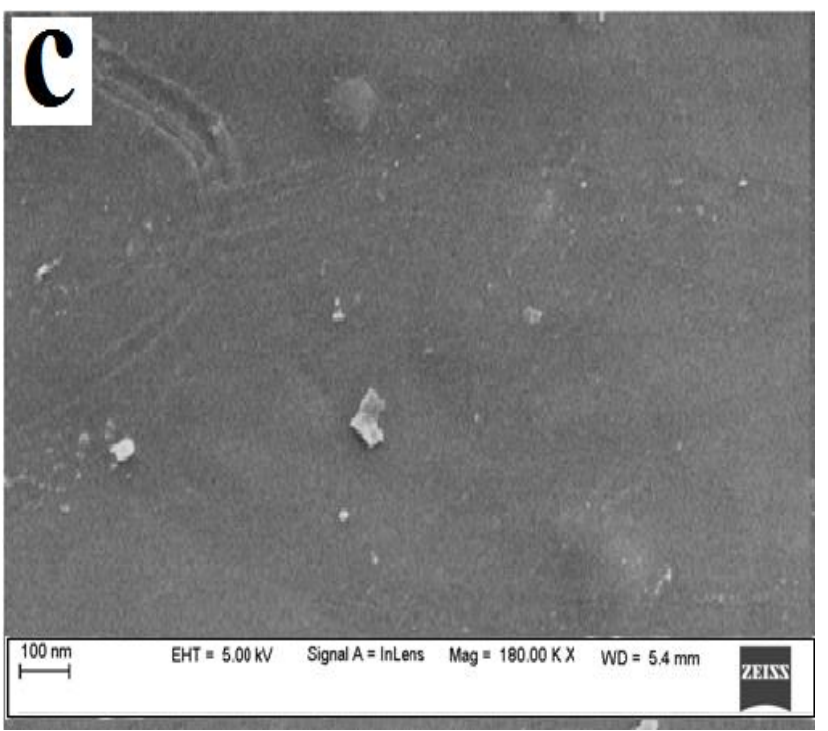

MC - maghemite composite, and 10/90 GG/MC blend-maghemite composite were recorded in the wavelength range of $4000-500 \mathrm{~cm}^{-1}$ (Fig. 13). Guar gum showed (Fig. 13a) the broad and strong absorption band at $3347.3 \mathrm{~cm}^{-1}$, the absorption band at $2918.2 \mathrm{~cm}^{-1}, 1638.3 \mathrm{~cm}^{-1}$ is due to the to $-\mathrm{OH}$ bond stretching, $-\mathrm{CH}$ group stretching, and $-\mathrm{OH}$ bond belonging to water molecules, respectively. The absorption band at $1370.9 \mathrm{~cm}^{-1}$ and $1012.7 \mathrm{~cm}^{-1}$ is the bending of $-\mathrm{CH}_{2}-\mathrm{O}-\mathrm{CH}_{2}-$ groups [23].

The FTIR spectra of MC (Fig. 13b) showed a $-\mathrm{OH}$ stretching at $3350.3 \mathrm{~cm}^{-1}$, and $1593.7 \mathrm{~cm}^{-1}$ is due the $-\mathrm{OH}$ bond belonging to water molecules. $\mathrm{C}-\mathrm{H}$ stretching of the $-\mathrm{CH}_{2}$ groups is observed at $2916.7 \mathrm{~cm}^{-1}$, a $-\mathrm{CH}_{2}$ scissoring around $1412 \mathrm{~cm}^{-1}$ and -O- stretching at $1026 \mathrm{~cm}^{-1}[24,25]$.

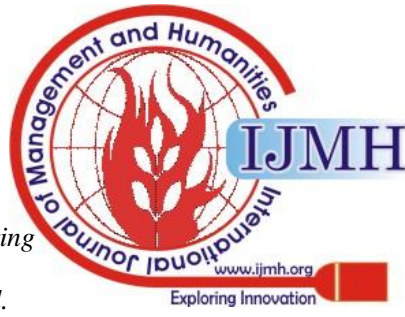



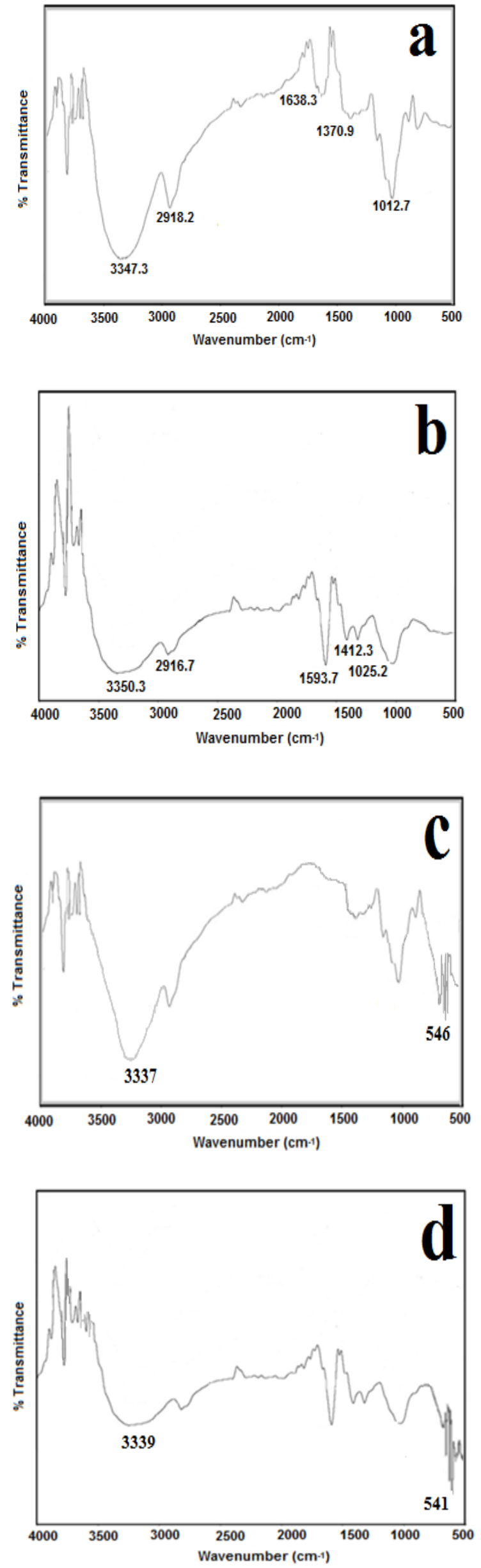

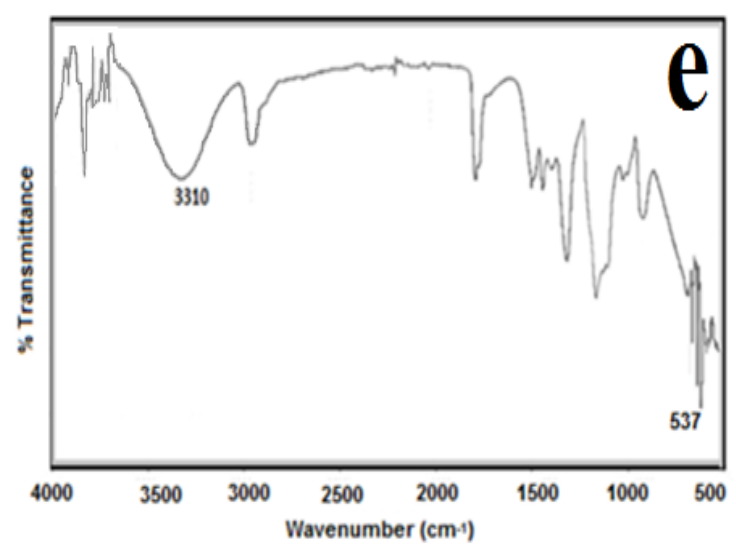

Fig. 13: FTIR spectra of a) GG, b) MC, c) GG-maghemite composite, d) MC-maghemite composite, and e) 10/90 GG/MC blend-maghemite composite

FTIR images (Fig. 13c, and Fig. 13d) showed the characteristic maghemite peaks in the GG - maghemite composite, and MC - maghemite composite. FTIR spectroscopy of 10/90 GG/MC blend - maghemite composite is given in Fig. 13e. The major peaks were associated with alcohol (v-OH) group observed at $3310 \mathrm{~cm}^{-1}$. Alkyl stretching, carbonyl group stretching, and $-\mathrm{CH}$ bending, -C-O stretch were observed at $2941 \mathrm{~cm}^{-1}, 1735 \mathrm{~cm}^{-1}, 1245$ $\mathrm{cm}^{-1}, 1088 \mathrm{~cm}^{-1}$, respectively. The peak at $537 \mathrm{~cm}^{-1}$ corresponds to the vibration of Fe-O, and the other peaks of pure maghemite are $454 \mathrm{~cm}^{-1}$, and $632 \mathrm{~cm}^{-1}$ [26-27]. The instrumental limitation did not allow these two peaks to be clearly shown. The hydroxyl characteristic bands for 10/90 GG/MC blend - maghemite composite got shifted to lower wavelength compared to GG and MC, which confirms the formation of H-bonding between guar gum and methylcellulose in the presence of maghemite. Hence, the FTIR spectroscopic measurement confirms that the incorporation of maghemite influenced the miscibility of GG/MC blend, and 10/90 GG/MC blend is miscible in the presence of $0.02 \mathrm{wt} \%$ maghemite.

\section{CONCLUSIONS}

Based on the refractive index, density, ultrasonic velocity, adiabatic compressibility, and dilute solution viscometry studies it is confirmed that guar gum and methylcellulose form immiscible blends. The influence of biocompatible magnetic nanoparticles on the miscibility of GG/MC was studied using density, ultrasonic velocity, adiabatic compressibility, and dilute solution viscometry in aqueous solution and with solution cast thin films by scanning electron microscopy and Fourier transform infrared spectroscopy. The results confirms that 10/90 GG/MC blend composition is miscible with the presence of maghemite nanoparticles. The formation of intermolecular hydrogen bonding between GG and MC in the presence of maghemite nanoparticles were confirmed with SEM and FTIR studies. The maghemite compatible blend composition of GG/MC will be having applications in drug release formulations.

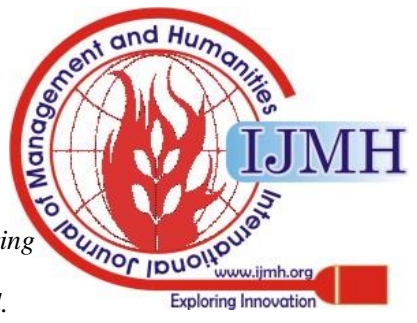




\section{REFERENCES}

1. W. J. Work, K. Horie, M. Hess, and R. F. T. Stepto, "Definitions of terms related to polymer blends, composites, and multiphase polymeric materials", Pure Appli. Chem., vol. 76, 2004, pp. 1985-2007.

2. J. M. G. Cowie, Miscibility in encyclopedia of polymer science and engineering. New York: Wiley Interscience Publication, 1989.

3. S. Krause, D. R. Paul, and N. Seymour, Polymer-polymer compatibility in polymeric blends. New York: Academic Press, 1978.

4. R. Garcia, O. Melad, C. M. Gomez, J. E. Figueruelo, and A. Campos, "Viscometric study on the compatibility of polymer-polymer mixtures in solution", Eur. Polym. J., vol. 35, 1999, pp. 47-55.

5. C. Rakkappan, and S. Anbalagan, "Ultrasonic and FTIR studies on aqueous biodegradable polymer blend solutions", American-Eurasian Journal of Scientific Research, vol. 4, 2009, pp. 281-284.

6. S. M. Gheno, F. R. Passador, and L. A. Pessan, "Investigation of the phase morphology of dynamically vulcanized PVC/NBR blends using atomic force microscopy", J. Appli. Polym. Sci., vol. 117, 2010, pp. 3211-3219.

7. Carla da Silva Meireles, R. Guimes Filho, M. N. Rosana de Assuncao, and Mara Zeni and Katia Mello, "Blend compatibility of waste materials - cellulose acetate (from sugarcane baggage) with polystyrene (from plastic cups): diffusion of water, FTIR, DSC, TGA and SEM study", J. Appli. Polym. Sci., vol. 104, 2007, pp. 909-914.

8. L. Daniliuc, C. De Kesel, and C. David, "Intermolecular interactions in blends of PVA with polyacrylic acid-1. FTIR and DSC studies", Eur. Polym. J., vol. 28, 1992, pp. 1365-1371.

9. P. Prasad, G. S. Guru, H. R. Shivakumar, and K. Sheshappa Rai, "Investigation on miscibility of sodium alginate/pullulan blends", Journal of Polymers and Environment, vol. 20 (3), 2012, pp. 887-893.

10. P. Prasad, G. S. Guru, H. R. Shivakumar, and K. Sheshappa Rai, "Miscibility, thermal, and mechanical studies of hydroxypropyl methylcellulose/pullulan blends", Journal of Applied Polymer Science, vol. 110, 2008, pp. 444-452.

11. G. S. Guru, P. Prasad, H. R. Shivakumar, and K. Sheshappa Rai, "Studies on the Compatibility of pullulan-carboxymethyl cellulose blend using simple techniques", Malaysian Polymer Journal, vol. 3 , 2008, pp. 3-23.

12. G. S. Guru, P. Prasad, H. R. Shivakumar, and K. Sheshappa Rai, Journal of Polymers and Environment, vol. 18, 2010, pp. 135-140.

13. Vishwanath Bhat, H. R Shivakumar, K. Sheshappa Rai, Sanjeev Ganesh, P. Prasad, G. S. Guru, and B. B. Bhavya, "Miscibility and thermal behavior of pullulan/polyacrylamide blends", Journal of Macromolecular Science, Part A, vol. 48, 2011, pp. 920-926.

14. M. S. Bhavya, M. B. Savitha, and P. Prasad, "Miscibility studies of GG/CMC blends in aqueous solution", International Journal of Advance Research in Science and Engineering, Vol. 6 (1), 2017, pp. 514-523.

15. P. Prasad, M. S. Bhavya, P. P. Abhijith, S. K. Sreelakshmi, and M. B. Savitha, "Physico-chemical and thermal property studies of GG/CMC blend thin films", International Journal of Advance Research in Science and Engineering, Vol. 6 (6), 2017, pp. 572-578.

16. P. Prasad, M. S. Bhavya, P. P. Abhijith, S. K. Sreelakshmi, and M. B. Savitha, "Miscibility studies of GG/PVA blends in aqueous solution", International Journal of Advance Research in Science and Engineering, Vol. 6 (9), 2017, pp. 1-8.

17. P. Prasad, M. S. Bhavya, Nagesh Bhat, Momin Ashraf, Krishnaraja Acharya, and M. B. Savitha, "Physico-chemical and thermal property studies of GG/PVA blend thin films", International Journal of Advance Research in Science and Engineering, vol. 7 (1), 2018, pp. $1-7$.

18. C. Chevillard, and M. A. V. Axelos, "Phase separation of aqueous solution of methylcellulose", Colloid Polym. Sci. vol. 275, 1997, pp. 537-545.

19. U. Hafeli, W. Schutt, J. Teller, and M. Zboraski, Scientific and Clinical Applications of Magnetic Carriers. New York: Plenum Press, 1997.

20. I. Safarik, and M. Safarikova, "Magnetic nanoparticles and biosciences", Monatsh. Chem., vol. 133, 2002, pp. 737-759.

21. A. K. Gupta, and M. Gupta, "Synthesis and surface engineering iron oxide nanoparticles for biomedical applications", Biomaterials, vol. 26, 2005, pp. 3995-4021.

22. C. C. Berry, and A. S. G. Curtis, "Functionalisation of magnetic nanoparticles for applications in biomedicine", J. Phys. D: Appl. Phys., vol. 36, 2003, pp. 198-206.

23. G. Dodi, D. Hritcu, and M. I. Popa, "Carboxymethylation of guar gum: synthesis and characterization", Cellulose Chem. Technol., vol. 45, 2011, pp. 171-176.

24. Muhammad Yasir Ali, Nisar Ur-Rahman, Muneeb Ahmad Idrees,
Sabeeh Mohsin, Saeed Ahmed, and Irshad Ahmed, "Sustained release of captopril from matrix tablet using methylcellulose in a new derivative form", Latin American Journal of Pharmacy, vol. 30 (9) 2011, pp. 1696-1701.

25. L. O. Rafael, G. V. Julia, S. B. Hernane, M. N. A. Rosana, R. F. Guimes, J. L. R. Sidney, and Younes Messadeqq, "Synthesis and characterization of methylcellulose produced from bacterial cellulose under heterogeneous condition", Journal of the Brazilian Chemical Society, vol. 26 (9), 2015, pp. 1861-1870.

26. J. F. Luna-Martínez, E. Reyes-Melo, V. Gonzalez-Gonzalez, C. Guerrero-Salazar, A. Torres-Castro, and S. Sepulveda-Guzman, "Synthesis and characterization of a magnetic hybrid material consisting of iron oxide in a carboxymethyl cellulose matrix", J. Appl. Polym. Sci., vol. 127 (3), 2013, pp. 2325-2331.

27. D. B. Mahesh, D. Raghunandan, S. Basavaraja, D. S. Balaji, Arunkumar Lagashetty, and A. Venkataraman, "Preparation and characterization of magnetic $\mathrm{Fe}_{2} \mathrm{O}_{3}$ " J. Metal. and Mater. Sci., vol. 52, 2010, pp. 209-214.

\section{AUTHORS PROFILE}

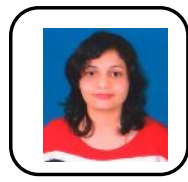

Bhavya M. S. completed her masters in Chemistry and pursuing her Ph.D. from Centre for Nano Science and Technology, Srinivas University, Mangaluru, India in the field of polymer blends, biocompatible polymers, and biocompatible nanocomposites. She has published five research articles entitled "Miscibility studies of GG/CMC blends in aqueous solution", "Physico-chemical and thermal property studies of GG/CMC blend thin films", "Miscibility studies of GG/PVA blends in aqueous solution", "Physico-chemical and thermal property studies of GG/PVA blend thin films", and "Applications of water-soluble polymer blends" in reputed international journals

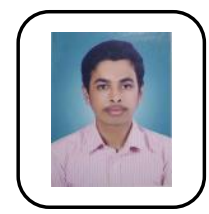

Sudhanva Narayana K. S. is pursuing his bachelor of engineering in Nano Technology from Srinivas Institute of Technology, Mangaluru, affiliated to Visvesvaraya Technological University, India.

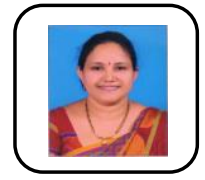

Savitha M. B. completed her master's degree and $\mathrm{Ph} . \mathrm{D}$. in Chemistry from Mangalore University, India. She has published many research articles in the field of spectroscopy, polymer blends, and nanomaterials. She has co-authored books in engineering chemistry and nanotechnology. She is the associate professor and head of the department of chemistry and research center at Sahyadri College of Engineering and Management, Mangaluru, affiliated to Visvesvaraya Technological University, India.

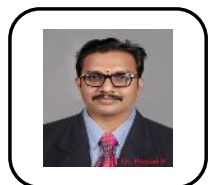

Prasad P. Completed his master's degree in Polymer Science from the University of Mysore, and Ph.D. in Applied Chemistry from Visvesvaraya Technologica University, India. He has published more than 25 research articles in the field of biocompatible polymers, polymer blends, and nanocomposites. He has served as professor and department head, department of Nano Technology and played a key role in establishing the bachelor degree syllabus under Visvesvaraya Technological University. He has also published 25 academic textbooks in the field of nanotechnology. Some of his book works include Applications of Nanotechnology, Foundations of nanoscale science and technology, Nanophotonics, Applications of bio-nanotechnology, Nanotechnology sensors and devices, Nanomaterials characterization, Basics of nanocomposites, nanotribology and fracture mechanics, Nanotoxicology, microfluidics and nanofluids, Synthesis and processing techniques, Synthesis of nanomaterials.

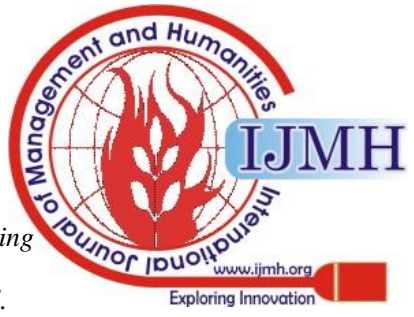

